\title{
QUANTIFYING BEDFORM MIGRATION USING MULTI-BEAM SONAR
}

\author{
M.A.F. KNAAPEN())
}

Water Engineering \&Mangement, University of Twente, P.O.Box 217, 7500 AE Enschede, The Netherlands.

M.A.F.Knaapen@utwente.nl

$+31-53-4892831$

$+31-53-4895377$

C.N. VAN BERGEN HeNEGOUW

Oceanographic Company of the Netherlands, Delft, The Netherlands.

Y.Y.HU

Dep. Technical Earth Sciences, University of Delft, The Netherlands.

\section{Abstract}

The migration rates of both medium and very large dunes in a part of the North Sea are determined from high resolution multi-beam echo soundings. From the bathymetric maps, crest positions are determined and compared. From changes in the position of these crests relative to fixed markers, the migration rates within a tidal cycle and on a seasonal time scale are calculated. The sediment transport rates derived from the migration of the bedforms compare well with theoretical estimates of the residual transport in the area.

\section{Introduction}

Sandy bottoms of shallow seas are commonly covered with a wide range of bedforms created by currents and wave action. The occurrence, size and dynamics of bedforms depend on the current velocity and water depth and on the availability a grain size of the sediments (e.g. Rubin and McCullock 1980; Flemming 2000). In offshore environments of the North Sea, a wide range of bedforms have been recorded. Reineck et al. (1971) classified four: ripples, mega-ripples, sand waves and sand banks. A fifth one, named long bedwaves, is described by Knaapen et al. (2001). These classifications are based on their distinct flow mechanisms. Here we are solely interested in the patterns sec. Therefore, we will follow the classification of Ashley (1990) distinguishing ripples, subaqueuos dunes and ridges. The dunes are subdivided based on their size, ranging from small to very large.

Often, bedforms migrate. Smaller dunes may migrate instantaneous due to the tidal flow (Engel and Lau 1980; Van Den Berg 1987). Larger dunes migrate over significant distances, when the ebb and flood velocities are unequal due to a superimposed residual current or a M4-related asymmetry. In case of a residual current, the flow velocities in the direction of that residual current are higher than the velocities in the opposite direction. This results in a residual current, a residual sediment transport and in dune migration (Németh et al. 2002). In the case of an asymmetrical tide, the flow velocities in one direction are higher than the velocities in the other direction, but the period in which occur is shorter. As a result the tideaveraged flow is zero, but a tide-averaged sediment transport does occur. The sediment 
transport depends on a power of the flow velocities, resulting in a larger transport in the direction of the highest velocities. The dunes migrate in this direction as well (Besio et al. 2004).

The migration of the smaller patterns, e.g. ripples and small and medium dunes, is an important factor in assessing nature's response to man-made interventions, both small-scale (such as fishery activities) and large-scale (such as sand and gravel extraction). Furthermore medium dunes are large enough to cover objects on the seabed such as lost cargo, monitoring equipment and mines.

Quantifying ripple migration by remote sensing has been the subject of study for many years, with limited success. Wever (2004) concludes that accurate observations are only possible with position control using solid markers placed on the seabed. Houthuys et al (1994) and Wever and Stender (2000) measured about 40 ripples using a single-beam echo sounder and a buried bed pressure sensor, respectively. The main difficulty has been to collect data on a sufficiently large number of small to medium dunes that will produce the necessary statistical parameters. Here, we discuss the potential of using detailed multi-beam sonar images in quantifying the migration of small to medium dunes in the presence of both fixed markers and very large dunes for reference.

\section{Study area}

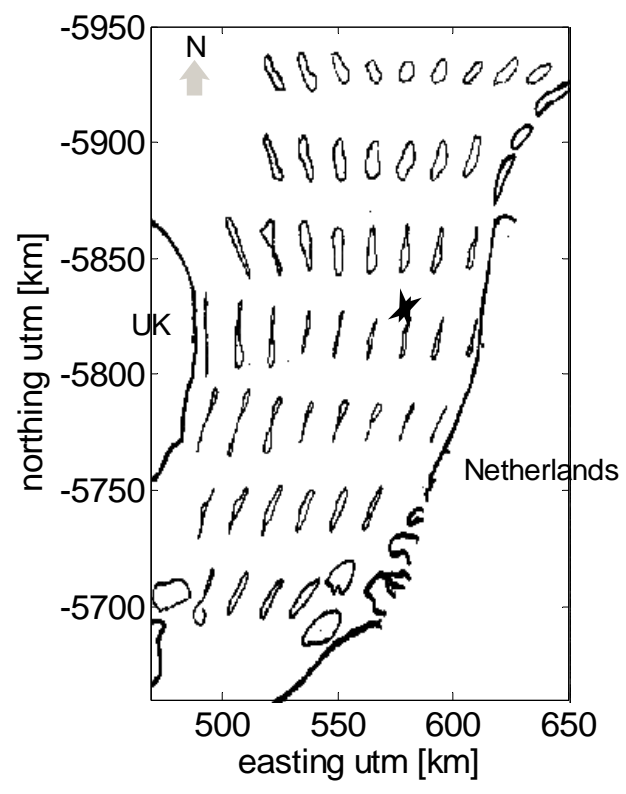

Figure 1. The multi-beam surveys are taken along a strip of 500 metre long and 75 metre wide at UTM km 556 east and 5831 north (black star). The ellipses are estimates of the tidal ellipses by McCave (1971)

Figure 1 shows the location of the study area at 52:37 latitude and 3:49 longitude $(5831 \mathrm{~km}$ northing and $556 \mathrm{~km}$ easting in UTM ED50) in the North Sea. The study area is a strip of 750 $\mathrm{m}$ by $75 \mathrm{~m}$. The research area is approximately 28 metre deep relative to mean sea level, with a tidal range of 0.8 metre. The average tide has a maximum depth-averaged tidal velocity of about $0.7 \mathrm{~m}$, but current velocities of about a meter might occur. The principal tidal axis has an approximately 15 degrees clockwise angle with the North. The waves are moderate with a mean wave height of 1.3 metre and only $10 \%$ of the waves exceed 2.5 metre (De Ronde et al., 1995).

The seabed consists completely of medium fine sand with a mean grain size of $275 \mu \mathrm{m}$. The sand is fairly well sorted with a $\mathrm{D}_{60} / \mathrm{D}_{10}$ ratio of 1.5 . The research area is within the region of 
the Holland banks (Roos et al. 2004) and on the bed small medium and very large dunes have been observed.

\section{Method}

In this paper the migration rate of the medium and very large dunes is determined based on the changes in the crest position of these dunes. A single track was surveyed repeatedly. From the resulting bathymetry data, the crest positions of the dunes are determined. The changes in the crest positions, corrected for positional errors in the surveys are analysed to deduce the migration rate of the dunes.

\section{Surveys}

The sea bed in a 750 metre long and 75 metre wide area was recorded 22 times divided over 2001 and 2002. In September 2001, twelve recordings were made every half hour, starting approximately one hour before high tide. Two additional surveys were taken two days later, with a 15 minute interval in between. Four recordings were taken in April 2002 with a fifteen minutes interval, starting approximately four hours after high tide. Again four recordings were taken in September 2002 with a fifteen minutes interval, starting at approximately high tide. The surveys were recorded using Simrad EM 3000 multi-beam sonar of the R.V. Arca. Simrad EM-3000 is a $300 \mathrm{kHz}$ system that fans out up to 121 beams at a $130 \mathrm{deg}$. angle, yielding swaths that are up to 4 times the water depth. The system can capture depths the 3$150 \mathrm{~m}$ range at survey speeds of 3-12 knots. The surveys were performed at a reduced speed of 4 knots and at the maximum ping rate of 25 pings per second. This resulted in an optimum resolution of 12.5 measurement points per square metre. All surveys were recorded in the same direction, except for two observations during the April 2002 routine. At depths of about 30 meter, the echo-sounder has an error of about 25 centimetres in the vertical, mostly related to the tidal correction and heave. At the sides of the measured strip the inaccuracy increases, an error related the increasing angle, resulting in a misalignment of the data points. For this reason, the outer 15 metres of the data have not been used.

The position has been determined using a DGPS positioning system. In offshore regions such as the research area, this system has a positional error up to about 2 meters (International Hydrographic Organization, 1998). The echo-sounding data were corrected for the migration speed of the sound, the tidal elevation and the motions of the ship. Extreme spikes are removed with a large threshold, to make sure that the signal of the marker was not removed from the data. The data received no other standard processing. They were stored in ASCII format as $\mathrm{x}-\mathrm{y}-\mathrm{z}$ records for each profile with the $\mathrm{x}$ and $\mathrm{y}$ co-ordinates in metres (UTM, ED50) and the $\mathrm{z}$ values in decimetres.

\section{Reduction of the positional error in the surveys.}

Due to the inaccuracy of the DGPS in this offshore area, the crest positions contain an error. To determine the position of the observed bedforms more accurately, a marker was placed on to the sea floor. The marker is a 1.5- metre diameter concrete-filled tyre mounted with a steel frame. The observed positions of the marker are used to correct for the inaccuracies in the positioning system, thus reducing the uncertainty associated with DGPS. This approach works well for the very large dunes. Since we have multiple surveys to determine the same crest position, we can reduce the positional error further by averaging the multiple estimates of the crest positions. Within the time frame of the survey sessions of a few hours, the migration of the very large dunes is negligible. Any observed displacement results from the positional error. 
The medium dunes do migrate in the period between the successive surveys. Therefore, we cannot average the position estimates of these dunes. The noise after correction relative to the marker is still too large. This noise is related to the uncertainty in the position of the marker. Alternatively, we use the crest positions of the very large dunes to correct the position of the medium dunes. Since we have multiple observations of the crest position within one survey, we can average the displacement of all these crest positions to get one accurate estimate of the positional error. The average observed displacement of the very large dunes is subtracted from the observed displacement of the medium dunes to get the best estimate of the mediumdune migration.

\section{Pattern recognition approach}

The authors present a method to determine the migration rate of medium and very large dunes based on a pattern recognition approach. The hypothesis behind this approach is that bedforms in a unidirectional flow regime will migrate as a group in the direction of the flow.

\section{Data reduction}

To reduce the amount of information in the data, a data reduction procedure is executed. In this procedure we characterise the dunes by the position of the crests and the troughs. If the dunes indeed migrate as a group, this will not result in any loss of information.

Each recording was interpolated to a rectangular grid, with a $0.35 \mathrm{~m}$ grid size, to allow for accurate comparison of the images and filtered using a low pass filtering (Manning window with 9 points in both directions for medium dunes and 75 points for the very large dunes). The size of the windows is such, that the underestimation of the wave height is negligible and large enough to reduce the impact of smaller scale bed forms and the remaining spiky errors. Next, the crest positions are identified as the local maxima along transects in the filtered data and the trough positions as the local minima. As a result the pattern of the dunes is represented by the position of the crests and troughs alone.

\section{Detecting Migration}

The crest lines formed by the data reduction procedure are analysed for migration. Using the assumption that the expected migration rate is small compared to the observed wavelength, the migration of the dunes can easily be determined from the displacement of the crest and trough positions following the approach of Knaapen (2004). Corresponding crest positions are compared and used to calculate the distance over which the pattern has travelled. The pattern recognition method is executed on both the medium and very large dune. Of course, the same procedure can be followed using the trough positions.

\section{Bedform related sediment transport}

Simons et al (1965) found a relationship between the sediment transport and the bedform migration rate and that the amount of bed-load sediment transport per metre related to bedform migration can be estimated with a simple formula: $s=\alpha c_{b} H\left[\mathrm{~m}^{2} / \mathrm{s}\right]$. This formula is based on the calculations of the amount of sediment that is transported when the bedform has travelled one wavelength, assuming zero transport in the troughs and no transport in the opposite direction anywhere on the profile. In this formula, $\alpha$ is the shape parameter, which is equal to 0.5 in case of triangular bedforms. In practice this parameter varies between 0.48 and 0.6 (Hoekstra et al. 2004). Engel and Lau (1980) showed that this formula still gives reliable 
transport rates even if there is flow separation resulting in sediment transport opposite to the mean flow direction. Somehow, the correction factors balance out.

\section{Results}

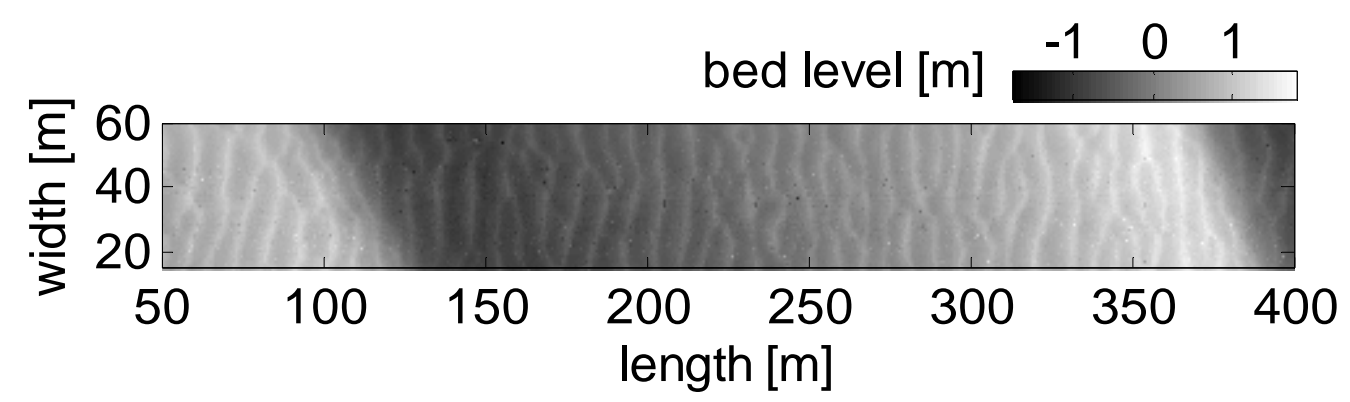

Figure 2. Observed bathymetry profile of September 2002. On top of the very large dunes medium dunes are visible

Three types of bedforms were recorded in the study area: ripples, medium dunes and very large dunes. In figure 2, the very large dunes are clearly visible. Upon close inspection, the medium dunes are recognisable as fine lineation at a small angle to the crest of the very large dunes.

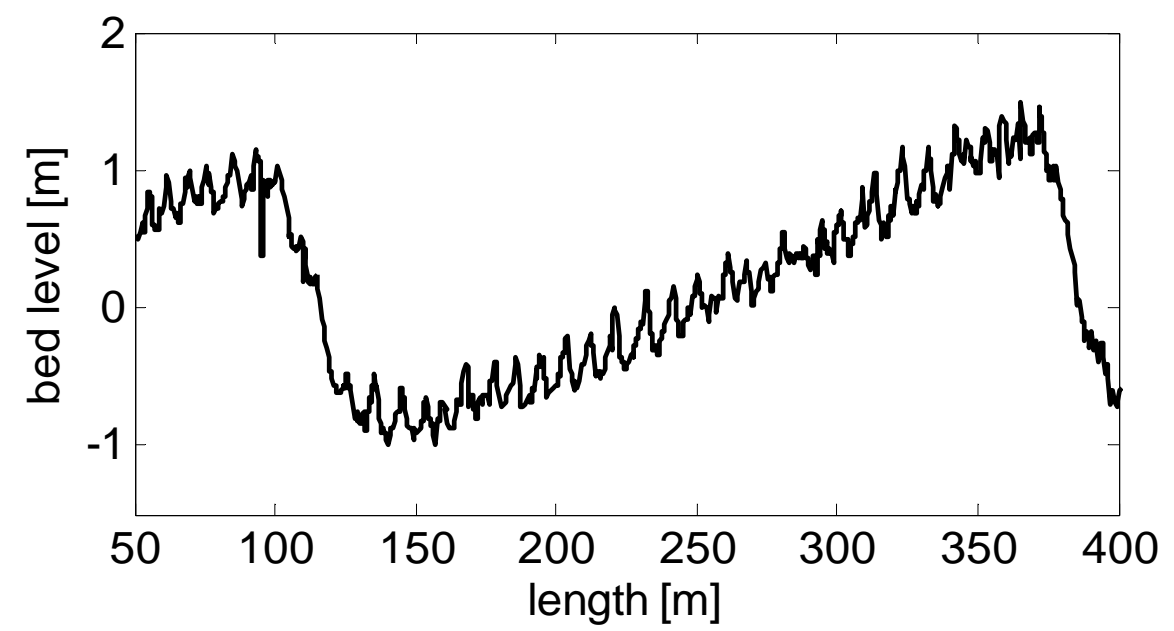

Figure 3. Cross-section of a very large dune with medium dunes superimposed (September 2002)

When the data are presented as a bathymetry cross section of a very large dune, the medium dunes are clearly visible as height modulations of about $10 \mathrm{~cm}$ (Error! Reference source not found.). Current ripples with similar heights can be seen superimposed on these medium dunes as well as some spiky measurement errors.

\section{Crest positions}

From the bathymetric maps the crest positions are determined. Here we will show some results for the medium dunes. The results for the very large dunes are similar. Figure 4 shows the crest positions of the medium dunes on the first and last survey of September 2001. Indeed the crest patterns are very similar and the displacement is small compared to the wavelength. 


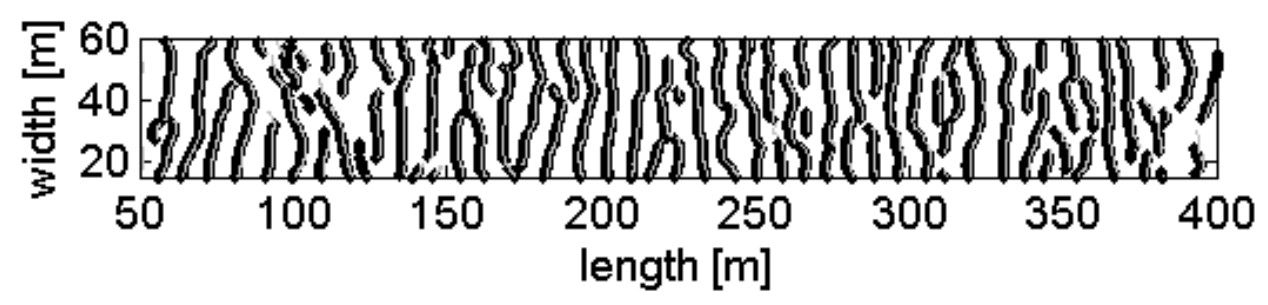

Figure 4. The crest and positions in the first survey (grey) and the fourth survey (black) of September 2002 are almost on top of each other

The distance between the matching crests in the two surveys are determined and plotted in a distance frequency graph (Error! Reference source not found.). From this distribution the average and the standard deviation of the displacements are determined.

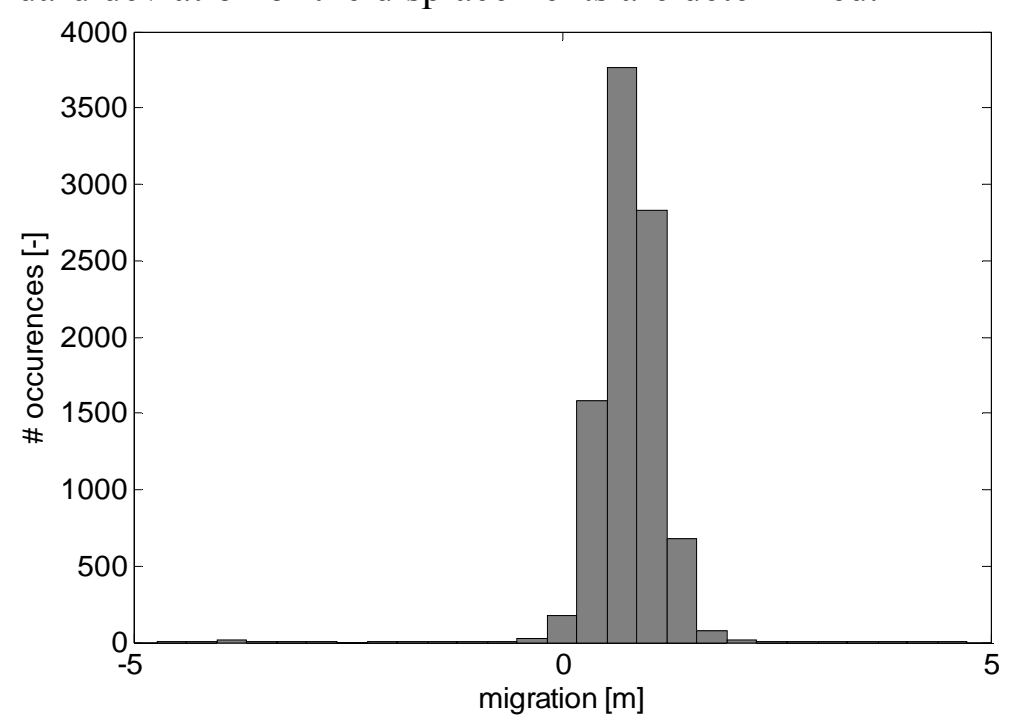

Figure 5. Distance frequency graph of the displacement of the crest positions between in the first survey and the fourth survey of September 2002

\section{Marker position}

Error! Reference source not found. shows the differences in the marker positions, relative to the first observation. The marker positions show two distinct clouds. The larger cloud contains the 14 observations of the September 2001 survey series. The other cloud contains the data of both other survey series. The two outliers at the bottom of the figure are the positions in the surveys taken from the opposite direction. The cause of the 3 metre difference is unclear. It is caused either by a change in the apparatus (different equipment, changed position or a new calibration) or by a displacement of the marker by storm waves. The latter, however, is very unlikely as the wave energy at $28-\mathrm{m}$ depth is not enough to displace the marker, even during major storms. 


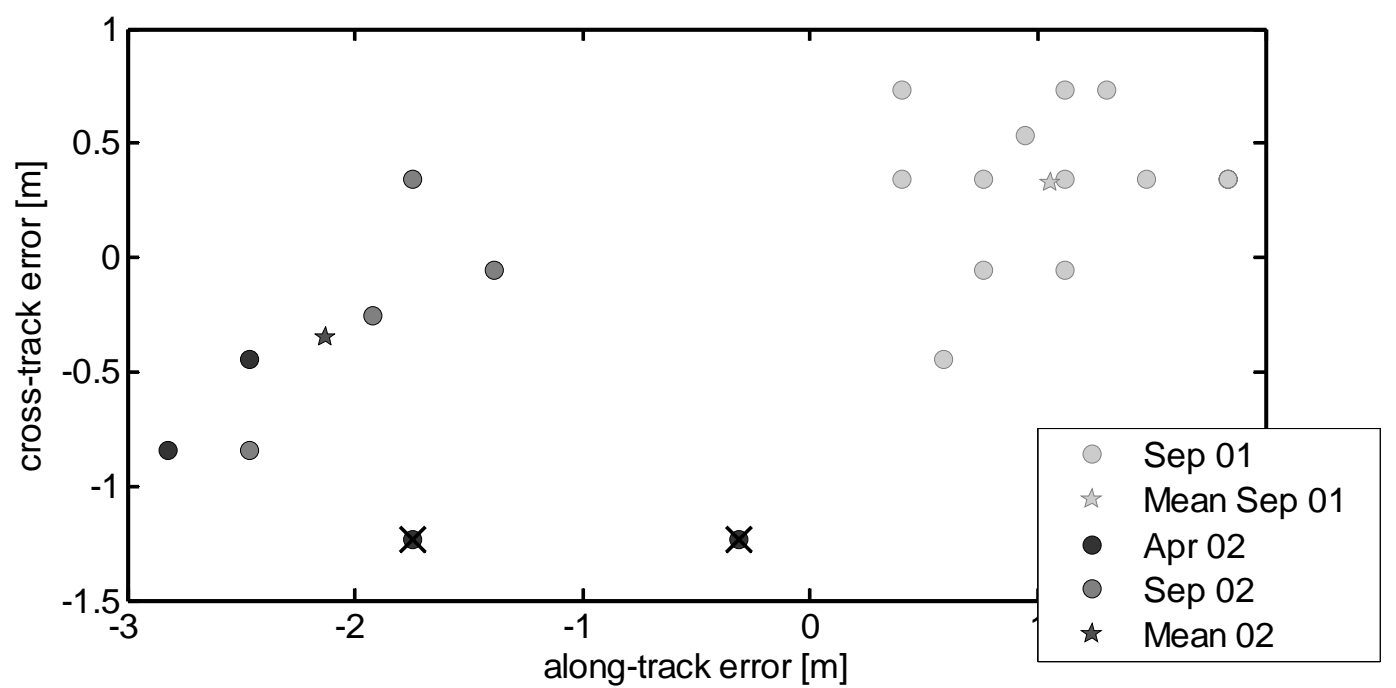

Figure 6. The observed positions of the marker mounted with a steel frame. In the determination of the mean position in 2002, the observations with the reverse survey direction (crosses) are neglected

\section{Very-large-dune migration}

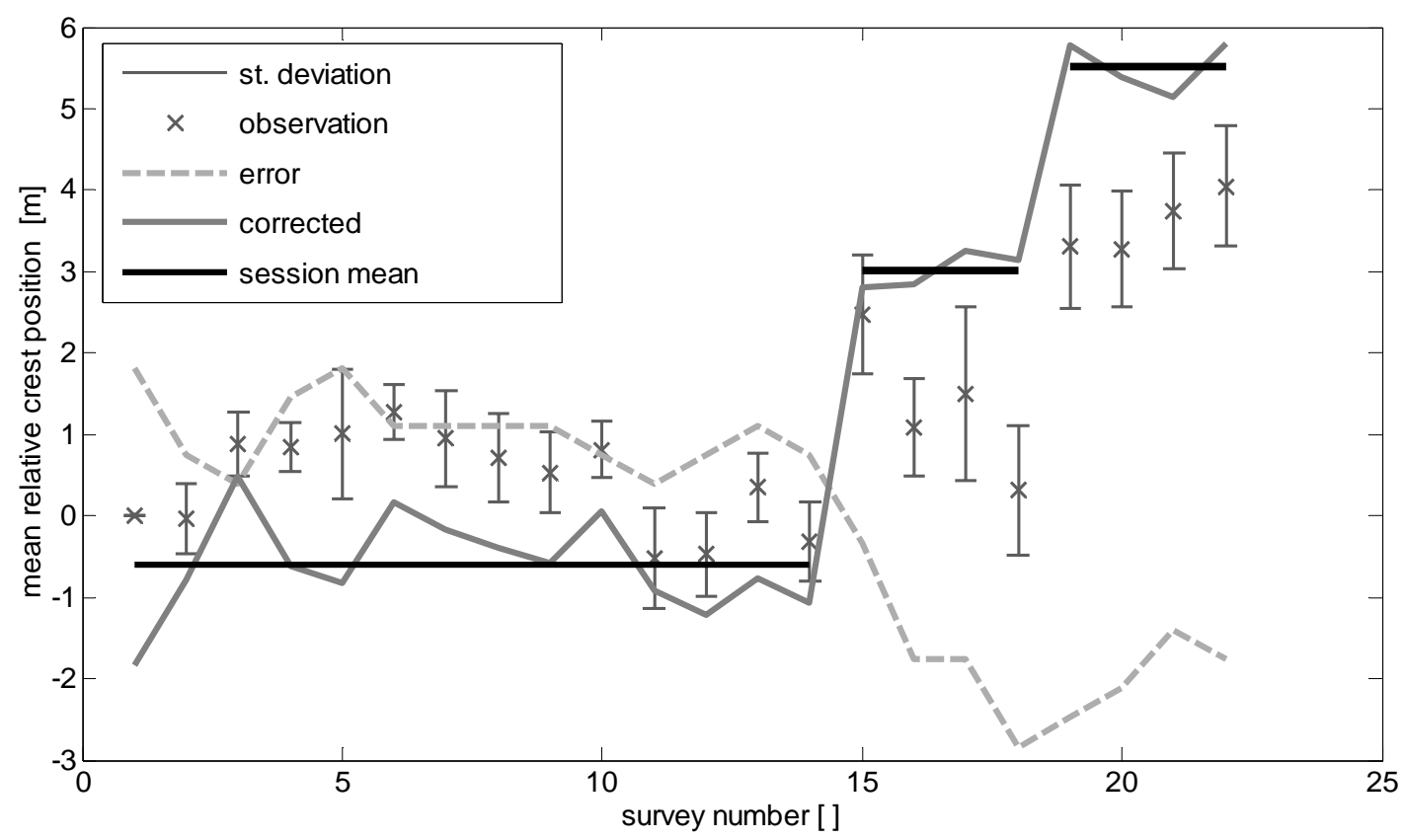

Figure 7. Cumulative migration $[\mathrm{x}]$ with standard deviation of the very large dunes for the 22 surveys during the research period. The solid gray line gives the values corrected for the positioning error (dashed line). The black lines give the sessional $\mathrm{m}$

Using the fixed marker approach, the changes in the position of the very large dunes are analysed. Figure 7 shows the average change in the observed crest positions relative to the first observation. The observations show a variability that is unrealistic for the short time scale on which the observations have been taken. After correction relative to the marker position, the variability reduces to errors of up to 1 metre. The migration between the different seasons shows a constant migration rate of $6.1 \mathrm{~m} / \mathrm{y}$ (Figure 8 ). The same analysis of the trough positions gives equal migration rates, but the standard deviation is doubled. 


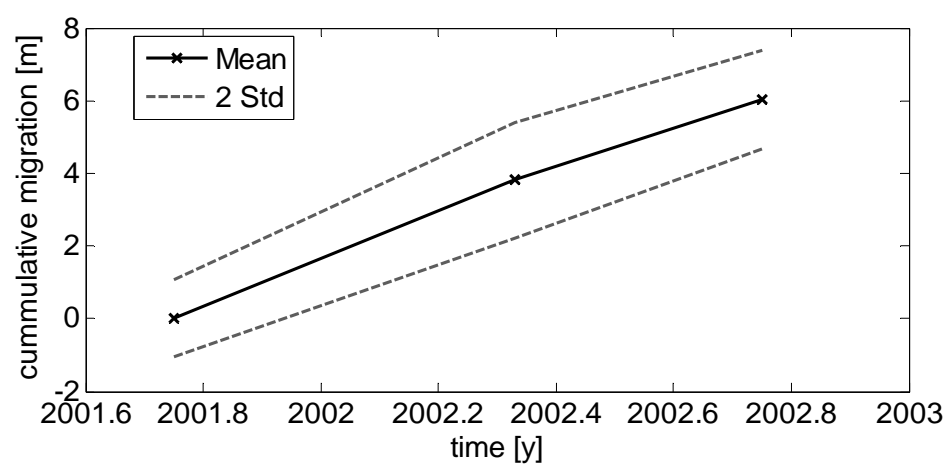

Figure 8. The mean cumulative migration (x) relative to the first survey session in September 2001 and the $95 \%$ confidence interval (dashed lines). Positive migration is towards the North-East

\section{Short term medium-dune migration}

The fixed marker method can also be used on the medium-dune patterns per season. In September 2001, twelve recordings were made every half hour starting approximately at high tide. The four recordings in April 2002 started approximately four hours after high tide and the four recordings in September 2002 started approximately at high tide. The two latter series cover a very short period (one hour). Consequently, the inaccuracies are too large to extract reliable migration rates for these series. The values found in April 2002 are even more obscured due to the fact that both the first and the third survey were undertaken using the opposite navigation direction. For these reasons, the analysis is restricted to the first series. As can be seen from Error! Reference source not found., there is still considerable noise in the corrected very-large-dune positions. These errors probably result from the single point estimates of the marker positions rather than from the dozens of estimates of the crests of the very large dunes. Within the survey period of six hours, the very large dunes may be assumed unchanged. Therefore, in this analysis the crest position of the very large dunes are used to correct the position of the medium dunes instead of the marker positions. 


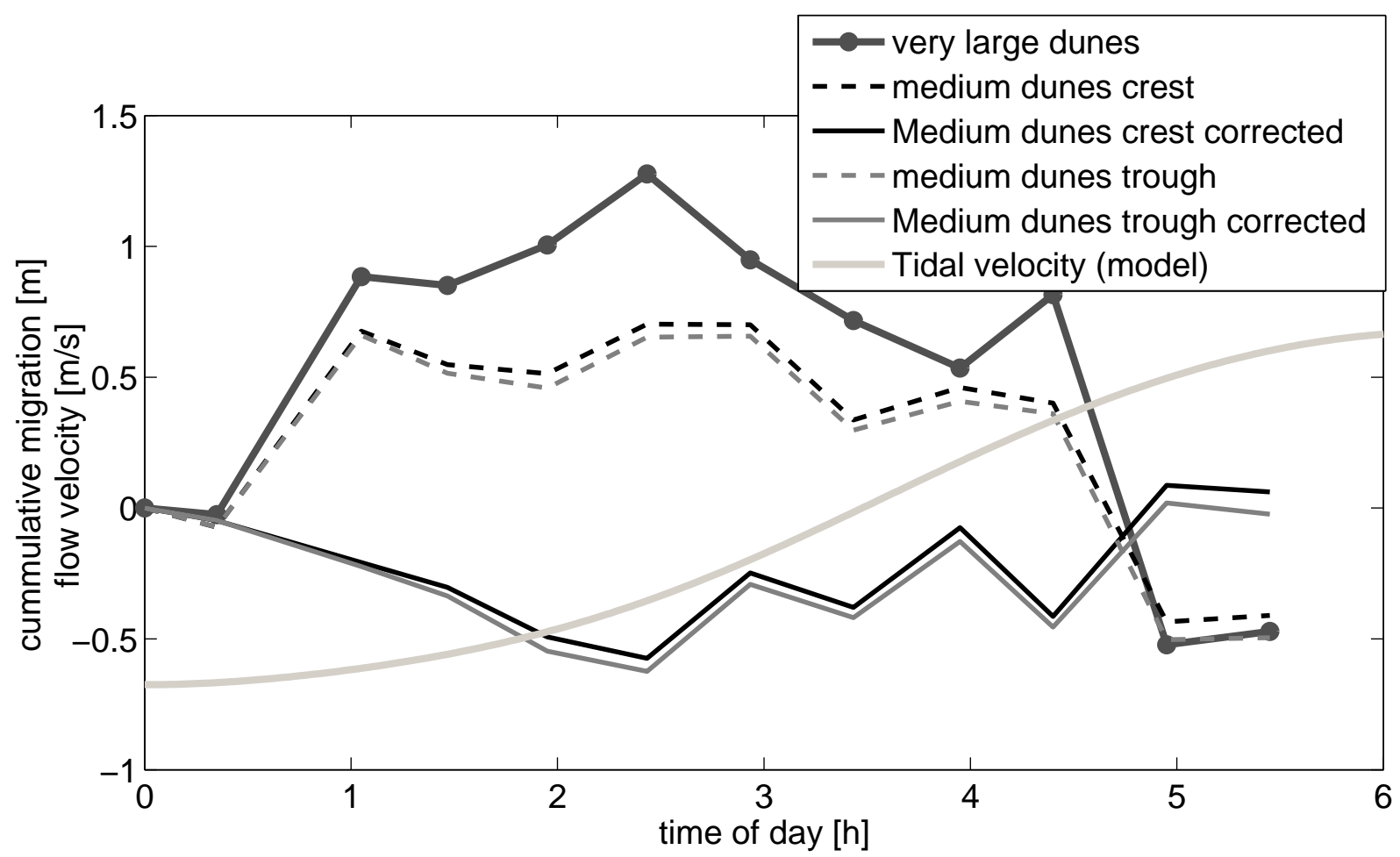

Figure 9. Cumulative migration of the medium dunes during the September 2001 series (dashed lines) for the crests (grey) and the troughs (black). The change in the position relative to the position of the sand wave crests (dark grey with dots) is given

Figure 9 shows the mean of the observed positions relative to the positions during the first survey. After correction, the medium-dune crest positions show a migration of up to $25 \mathrm{~cm}$ per hour. Note that the direction of medium-dune migration after correction is opposite to the apparent migration direction before the correction. This demonstrates the importance of the position correction. After correction, the migration correlates well with the tides. The migration direction changes after about three hours, which is about the time at which the flow direction changes according to the Continental Shelf model described by Heemink et al. (2002). Before high tide, the migration is directed southwards, the direction from which the tidal waves propagate. A more detailed analysis is impossible, however, as no current measurements are available. The analysis of the trough positions gives almost the same results. This shows that the shape of the medium dunes does not change during this part of the tidal cycle.

\section{Long term medium-dune migration}

In the long term, the assumption that medium dunes migrate as a group is not completely valid. The 2001 data contains a medium-dune pattern with an average wavelength of $9 \mathrm{~m}$. The two series in 2002 have longer wavelengths, reading almost $11 \mathrm{~m}$. These length differences are significant and one has to conclude that the pattern has changed completely. This makes it impossible to correlate the patterns to determine the migration. The two series in 2002 have equal wavelengths.

However, following the pattern recognition approach migration estimates have a distribution that is far from Gaussian. Consequently, the pattern formation procedure does not provide a migration estimate. The plan view of the medium dunes has changed substantially, due to variations in migration rates and local changes in the singular points of the pattern. 
(a)

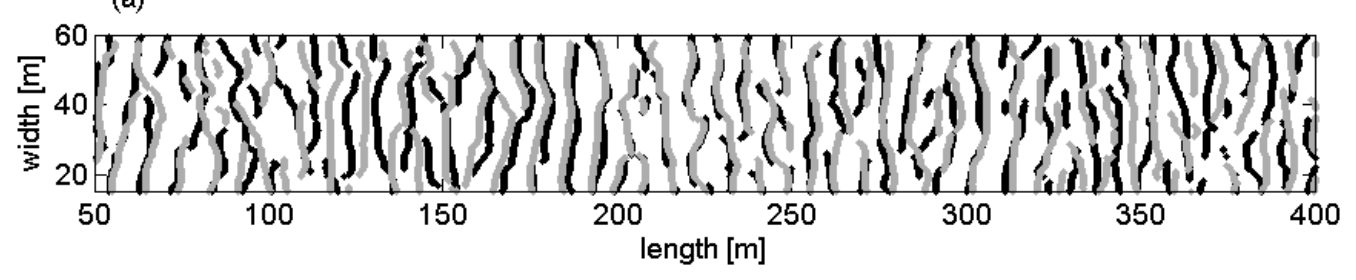

(b)

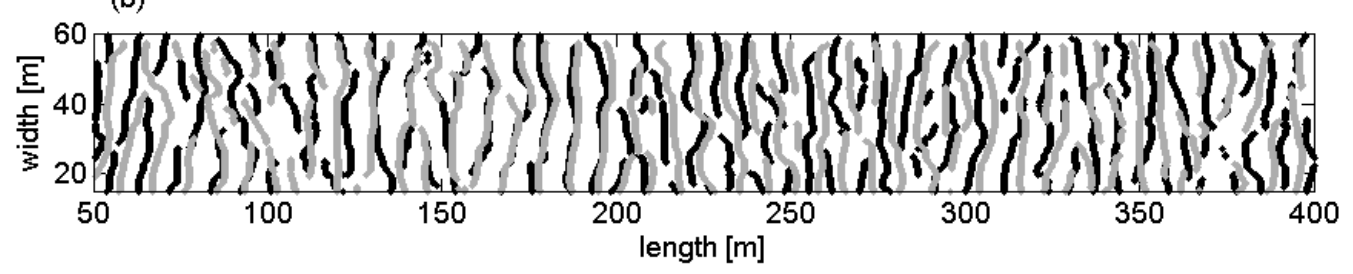

Figure 10. Medium dune crest observed in surveys 18 (black) and 19 (grey). For survey 18, the plotted crest positions correspond with the observed position, whereas the crests of survey 19 have been shifted $17.5 \mathrm{~m}$ (a) and $14 \mathrm{~m}(\mathrm{~b})$ to the left. The agreeme

Visually however, the patterns are still recognisable. Figure 10 shows the crest positions of surveys 18 and 19. The crests of survey 18 are shown as observed, whereas the crests of survey 19 have been shifted relative to their observed position.

In the top part, in which survey 19 has been shifted by 17.5 metre to the left, the crests align well between metres 210 and 300. This region corresponds with the stoss-slope of a very large dune. The migration rate of the medium dunes in this area is 17.5 metres. In the lower part, the crests of survey 19 are shifted by 14 metres to the left. The alignment of the crests between metres 130 and 210 shows that the migration rate is 14 metres in the trough of a very large dune. On the crest of the very large dune (metres 90 to 130) there is only limited agreement.

\section{Bedform related sediment transport}

The very large dunes in the research area are close to a triangular shape, with shape parameter $\alpha=0.51$. The medium-dunes have more rounded crests resulting in a shape parameter $\alpha=$ 0.54 .

In the survey series of September 2001, the medium dunes have a height $H$ of $0.08 \mathrm{~m}$ and a migration rate $c_{b}$ of roughly $0.25 \mathrm{~m} / \mathrm{h}$. These values result in an instantaneous sediment transport rate of about $310^{-6} \mathrm{~m}^{2} / \mathrm{s}$ or $0.011 \mathrm{~m}^{2} / \mathrm{h}$.

To estimate the residual transport, two estimates are available: a medium-dune related and a very-large-dune related sediment transport. The long-term migration rate of the medium dunes is approximately $42 \mathrm{~m}$ per year (17.5 $\mathrm{m}$ in 5 months). This results in a bedform related sediment transport of $3.2 \mathrm{~m}^{2} / \mathrm{y}\left(H=0.14, c_{b}=36 \mathrm{~m} / \mathrm{y}, \alpha=0.54\right)$. In the same period, the migration rate of the very-large dunes is 2.4 metre resulting in a migration rate of 5.8 metre per year. With this value, the net sediment transport rate is $5.2 \mathrm{~m}^{2} / \mathrm{y}\left(\mathrm{H}=1.78 \mathrm{~m}, \mathrm{c}_{\mathrm{b}}=5.8 \mathrm{~m} / \mathrm{y}\right.$, $\alpha=0.51)$.

\section{Discussion}

A thorough analysis of a series of detailed bathymetric surveys has revealed interesting information of the migration of medium and very large dunes. However, a number of questions remain. As it was impossible to undertake any flow measurements in the survey 
area, it is difficult to link the migration with the hydrodynamic conditions. An analysis of the tidal information of nearby measurement stations suggests that the migration agrees with the flow direction.

\section{Dune migration}

In earlier work by Baptist et al. (2001), no significant migration of the crests of both medium and very large dune could be determined when using a cross-correlation method on the data sets of September 2001 only. It was possible, however, to visualise current ripple migration. Although the height of the ripples is only slightly larger than the measurement noise and the wavelength is of the same order of magnitude as the resolution of the surveys $(0.35 \mathrm{~m})$, the periodicity of these ripples made it possible to estimate the migration rate. The highest correlation between successive measurements suggested a migration rate of about $0.25 \mathrm{~m} / \mathrm{h}$ (Baptist et. al. 2002). However, precise migration rates could not be given. This value is very close to the value for dune migration in this research. Perhaps, the ripples of Baptist et al. (2002) are merely the sharper edges of the medium dunes removed from the data in their filtering procedure.

In principle, the procedure to determine dune migration is sensitive to aliasing. If the migration is more than a single wavelength, the observed migration will be determined relative to the nearest crest position resulting in the wrong distance. However, all crest lines are different. These differences result in an almost uniform distribution of the observed migration with a much larger standard deviation. This makes aliasing easy to detect. The long term migration rate of the medium dunes depends on the position on the very large dunes. This relation is in agreement with the theory on the development of very large dunes. Komarova and Hulscher (2000) describe a current pattern near the sea floor, which produces a weak residual flow from the troughs to the crests. Consequently, flow velocities, related sediment transport and medium-dune migration are marginally larger on the slopes than in the troughs. The observations in this research confirm the theoretical results of Hulscher and Komarova (2000).

\section{Reliability}

In the observation as well as in the determination of the crest and trough positions some errors are introduced. As a result, the resulting positions have errors that are comparable to the magnitude of the migration rates. Still accuracy of the migration rates is high enough. As the patterns migrate as a group, a large number of observations can be averaged to find a single migration value. The number of medium dunes is such that the $95 \%$ confidence interval of the mean crest position within a single survey is only 2 centimetre. The confidence interval of the mean crest position of the very large dunes is 5 centimetre. The trough positions of the very large dune are known less accurate. The presence of the medium dunes has a larger effect on the noise in the troughs, which are relatively flat.

Consequently, the $95 \%$ confidence interval around the migration estimates of medium dunes is less than 10 centimetre. This is still comparable to the found migration rate of $25 \mathrm{~cm} / \mathrm{hr}$ and explains the 'noise' in the migration path, but small enough to have confidence in the trend visible with an initial southward migration followed by a northward path with an average of about $25 \mathrm{~cm} / \mathrm{hr}$.

The error in the migration rate of the very large dunes is dominated by the positional error in the DGPS. This is partly reduced using the fixed marker, resulting in a $95 \%$ confidence interval of about 1 metre around the observed values. However, the trend of 6 metre per year clearly exceeds the error band. 
It is difficult to estimate the accuracy of the long trend migration of the medium dunes. The visual interpretation clearly shows a migration that depends on the position on the very large dunes and is about 35 to 40 metre per year. However, exact values of the long-term migration rate cannot be given.

\section{Bedform related sediment transport}

The observed values dune shape parameter are in agreement with the various factors found in literature, which range from 0.48 to 0.60 (Hoekstra et al, 2004; van den Berg, 1987; Engel and Lau, 1980; Simons et al, 1965).

The residual transport related to medium dunes and the residual transport related to the very large dunes differ, with the latter being $60 \%$ of the former. This can easily be explained. The observed slopes of the dunes are relatively low, which implies that there is no flow separation. Consequently, it is not certain that a point on the profile exists where the tide-averaged sediment transport is zero. Therefore, the observed migration rates represent lower limits of the tide-averaged residual sediment transport.

This might also explain why these values for the long-term residual transport are considerably lower than the theoretical results of Van Der Molen (2002). His North Sea sediment transport model estimates a net transport of about $30 \mathrm{~m}^{2} / \mathrm{y}$ in the research area. Within this total transport, the calculations of Van Der Molen (2002) gave a ratio between suspended load and bed load transport of 2 to 3 in the area, which implies that the magnitude of the bed load transport, which dominates the very-large-dune dynamics (Bijsterbosch et al., 2004), would be 7.5 to $10 \mathrm{~m}^{2} / \mathrm{y}$. This is only a factor 2 or 3 of the estimated bedform related sediment transport, which is well within the common range of differences between theoretical sediment transport formulations and observations.

Bedform migration does not always have to be in the same direction as the net sediment transport. Anti-dunes, for example, migrate upstream the direction of the sediment transport. For low Froude numbers however, the assumption that bedforms generally migrate in the direction of sediment transport seems valid. This assumption is confirmed by the work of Németh et al. (2002) and Besio et al. (2004). This research confirms the assumption as well. The direction and magnitude of the (tide-averaged) migration of the dunes agrees with the assumed direction of the (residual) sediment transport as found by Van der Molen (2002). This suggests that the short-term medium-dune migration is correlated to the instantaneous sediment transport and the long-term migration to the residual sediment transport. By implication this means that from short-term medium-dune migration the long-term sediment transport can be estimated, which would only require averaging over a tidal cycle, or perhaps over a neap-spring cycle. However, more information is needed over the variation in mediumdune migration for varying flow velocities. This condition could be fulfilled by carrying out a number of survey series during several stages within the neap-spring cycle, in which a large part of the tidal cycle is covered for each series. Preferably, this should be accompanied with local flow information.

\section{Conclusions}

In this paper we have shown that offshore submarine dune migration can be observed using multi-beam echo-soundings. Sufficient resolution to detect small changes in the bathymetry related to medium-dune migration can be achieved. For reliable results, however, accurate positioning is required. For very large dunes, this is achieved using markers. For medium dunes the presence of very large dunes in the survey area gives the best positioning check. 
Table 1. Dimensions and migration rate of bedforms observed in the research area

\begin{tabular}{|l|r|r|r|r|}
\hline Bed form & Length & Height & \multicolumn{2}{|c|}{ Migration Rate } \\
\hline Ripples & $0.5 \mathrm{~m}$ & $0.01 \mathrm{~m}$ & $?$ & $?$ \\
\hline Medium dunes & $11 \mathrm{~m}$ & $0.09 \mathrm{~m}$ & $?$ & $40 \mathrm{~m} / \mathrm{y}$ \\
\cline { 2 - 5 } & $9 \mathrm{~m}$ & $0.14 \mathrm{~m}$ & $0.25 \mathrm{~m} / \mathrm{h}$ & $?$ \\
\hline Very large dunes & $250 \mathrm{~m}$ & $1.8 \mathrm{~m}$ & 0 & $6 \mathrm{~m} / \mathrm{y}$ \\
\hline
\end{tabular}

On the short-term medium dunes migrate as a group. Both the crest patterns and the trough patterns remain intact. This allows the pattern recognition approach to determine the migration rate, which is about 25 centimetres per hour. The same approach gives a migration of the very-large-dunes of 6 metre per year. Table 1 summarizes the dimensions and migration rates of the bedforms observed in this research.

In the longer term, the migration rate of the medium dunes varies based on the position of the medium dunes on the very large dunes. In the summer, the medium dunes on the slope of the very large dunes migrate faster than those in the troughs: 17 and 14 metre in five months, respectively. On the crests the patterns have changed too much to determine a migration rate. The variability in the long-term migration rate corresponds well with the residual flow circulation related to the occurrence of very large dunes described by Komarova and Hulscher (2000).

In winter, the medium-dune pattern has changed significantly. Although it is not possible to explain this change, it is most likely a result of high energy storm events.

The instantaneous transport rate, determined from the short-term migration, is $0.014 \mathrm{~m}^{2} / \mathrm{h}$. The residual transport rate, derived from the long-term migration is $19 \mathrm{~m}^{2} / \mathrm{y}$. These values are close to the theoretical values calculated by Van Der Molen (2002). The very-large-dune related sediment transport is smaller (only $4.5 \mathrm{~m}^{2} / \mathrm{y}$ ). This implies that not all residual sediment transport contributes to the very-large-dune dynamics.

\section{Acknowledgement}

Several people with the Directorate-General of Public Works and Water Management, North Sea Directorate, have been instrumental in data acquisition and data processing. In particular we would like to thank S.L. Bicknese for co-ordinating the processing of multi-beam data and T. Krijthe for supervising data acquisition on board the R.V. Arca. The research project was part of Delft Cluster Theme 3: Coast and River; Eco-morphodynamics of the seafloor (project number: 03.01.05). We also would like to thank project co-ordinator S. van Heteren (TNO\NITG), for his valuable comments.

\section{References}

Ashley GM (1990) Classification of large-scale subaqueous bedforms: a new look at an old problem. Journal of Sedimentary Petrology 60: 160-172

Baptist MJ, van Bergen Henegouw CN, Boers M, van Heteren S, Hoogenwoning S, Hulscher SJMH, Jacobs JJ, Knaapen MAF, Mulder M, Passchier S, van der Spek AJF and Storbeck F (2001) Eco-morphodynamics of the Seafloor, Delft Cluster, Theme 3 Coast and River, Progress report 2000.

Baptist MJ, van Bergen Henegouw CN, Bijker R, van Dalfsen, JA, van Damme RMJ, van Heteren S, Holzhauer H, Hulscher SJMH, Kaag, NHBM, Knaapen MAF, Lewis W, Morelissen R, Németh AA, Passchier S, van der Spek AJF and Weber A (2002) Eco-morphodynamics of the Seafloor, Delft Cluster, Theme 3 Coast and River, Progress report 2001.

Besio G, Blondeaux P, Brocchini M and Vittori G (2004), On the modelling of sand wave migration. Journal of Geophysical Research 109: C04018.

Bijsterbosch LWW, Németh AA and Hulscher SJMH (2004) Modelling offshore sand waves: Effect of suspended sediment transport. In: Hulscher SJMH, Garlan TE and Idier D (Ed.), Proceedings Marine Sandwave Dynamics. University of Twente: 24-31. 
De Ronde JG, Van Marle JGA, Roskam AP and Andorka Gal JH Golfrandvoorwaarden langs de Nederlandse kust op relatief diep water. Rapport RIKZ-95.024, Rijkswaterstaat, Rijksinstituut voor Kust en Zee/RIKZ.

Engel P and Lau YL (1980) Computation of bedload using bathymetric data. Journal of the Hydraulics Division 106: 369380 .

Flemming BW (2000) The role of grain size, water depth and flow velocity as scaling factors controlling the size of subaqueaus dunes. In: Trenteseaux A and Garlan TE (Ed) Proceedings Marine Sandwave Dynamics. University of Lille: $55-$ 60 .

Heemink AW, Mouthaan EEA, Roest MRT, Vollebregt EAH, Robaczewska KB, Verlaan M (2002) Inverse 3D shallow water flow modelling of the continental shelf. Continental Shelf Research 22 (3): 465-484.

Hoekstra P, Bell P, van Santen P, Roode R, Levoy F, Whitehouse R (2004) Bedform migration and bedload transport on an intertidal shoal. Continental Shelf Research 24: 1249-1269.

Houthuys, R and Trenteseaux, A and De Wolf, P (1994) Storm influences on a tidal sandbank's surface. Marine Geology 121: 23-41.

International Hydrographic Organization (1998) IHO standards for hydrographic surveys, International Hydrographic Organization Special Publication 44, International Hydrographic Bureau, Monaco.

Knaapen MAF, Hulscher SJMH, de Vriend HJ and Stolk A (2001). A new type of sea bed waves, Geophysical Research Letters 28 (7): 1323-1326.

Knaapen, MAF (2004) Measuring sand wave migration in the field. Comparison of different data sources and an error analysis. In: Hulscher SJMH, Garlan TE and Idier D (Ed.), Proceedings Marine Sandwave Dynamics. University of Twente: 152-159.

Komarova NL and Hulscher SJMH (2000) Linear instability mechanics for sand wave formation. Journal of Fluid Mechanics 413: 219-246.

McCave N (1971) Sandwaves in the North Sea off the coast of Holland. Marine Geology 10: 199-225.

Németh AA, Hulscher, SJMH and de Vriend HJ (2002) Modeling sand wave migration in shallow shelf seas. Coninental Shelf Research 22 (18-19): 2795-2806.

Reineck HE, Singh IB and Wunderlich F (1971). Einteilung der Rippeln und anderer mariner Sandkörper. Senckenbergiana maritima 3: 93-101.

Roos PC, Hulscher SJMH, Knaapen MAF and Van Damme RMJ (2004) The cross-sectional shape of tidal sandbanks: Modeling and observations. Journal of Geophysical Research 109: F02003.

Rubin DM, McCullock DS (1980) Single and superimposed bedforms: a synthesis of San Fransisco Bay and flume observations. Sedimentary Geology 26:207:231.

Simons DB, Richardson EV, Nordin CF Jr (1965) Bedload equation for ripples and dunes. Professional paper 462-H, USGS. Van den Berg JH (1987). Bedform migration and bed load transport in some rivers and tidal environments. Sedimentology 34: 681-689.

Van der Molen J (2002) The influence of tides, wind and waves on the net sand transport in the Norht Sea. Continental Shelf Research 22: 2739-2762.

Wever ThF and Stender IH (2000). Strategies for and results from the investigation of migrating bedforms in the German Bight. In: Trenteseaux A and Garlan TE (Ed.), Proceedings Marine Sandwave Dynamics. University of Lille: 221-226. Wever ThF (2004) Bedforms and bedform migration: a data review. In: Hulscher SJMH, Garlan TE and Idier D (Ed.), Proceedings Marine Sandwave Dynamics. University of Twente: 330-337. 
